\title{
Erratum to: Multiculturalism, Multilingualism and the Self
}

\author{
Danuta Gabryś-Barker, Dagmara Gałajda, Adam Wojtaszek \\ and Pawel Zakrajewski
}

\section{Erratum to: \\ D. Gabryś-Barker et al. (eds.), Multiculturalism, Multilingualism and the Self, Second Language Learning and Teaching, DOI 10.1007/978-3-319-56892-8}

In the original version of the book, newly received corrections have to be incorporated in Chapters 4 and 6 . The erratum book has been updated with the changes.

The updated online version of this book can be found at

http://dx.doi.org/10.1007/978-3-319-56892-8 